\title{
Cassava Starch-Based Composite Reinforced with Coconut Mesocarpfibers: Analysis of Physicochemical Stability
}

\author{
Ahmed Doumbia ${ }^{1}$, Pierre J.-M. R. Dable ${ }^{2}$ \\ ${ }^{1}$ Faculty of Environment, Jean Lorougnon Guédé University, Ivory Coast \\ ${ }^{2}$ Houphouet-Boigny National Polytechnic Institute, Department of Mechanical and Energy Engineering, Ivory Cost
}

\begin{abstract}
In one of our previous articles, we developed a cassava starch material reinforced with coconut mesocarpfibers. Its properties have been evaluated. It appears that the behavior of the composite depends on the atmospheric conditions of exposure. The purpose of this work is to do a more in-depth physicochemical stability analysis. To do this, identical samples were exposed in different chemical environments: basic, saline, acidic and distilled water. The mass losses are measured after 75 days of immersion in the different solutions in three cases: films without addition of lime and fibers, film with the presence of lime and without reinforcements, and finally the composite with lime and fibers. We observe that, in all cases, the loss of mass decreases with the addition of lime and fibers. However, in the basic solution, this decrease is greater $(53.4 \%)$ while it remains acceptable in a saline environment (1.1\%). In short, this material can be used for several applications in the field of packaging such as the preservation of dry salty products.
\end{abstract}

KEYWORDS: Cassava Starch, Coconut Fibers, Physicochemical Stability.

\section{INTRODUCTION}

The term chemical stability refers to the resistance of a material to chemicals. It is therefore about the material's ability to resist the destruction process triggered by reactions between the environment and the surface. Indeed, if the material is subjected to chemical stress where its chemical resistance is insufficient, this can lead to or accelerate its destruction. Under these conditions, objects made from such material can suffer negative consequences on its life or failure. The objective of this manuscript is to analyze the deterioration behavior of a cassava starch material reinforced with coconut mesocarpfibers developed during the work of one of our previous articles [1]. To do this, the composite is exposed in different chemical environments. These are basic, acidic and saline solutions, and distilled water. The analysis is made by determining the loss of mass during 75 days of immersion. It is observed that the composite behaves better in a saline environment while it exhibits a very great loss of mass in basic solution. In conclusion, this material can be used for different uses in the field of packaging.

\section{METHODOLOGY}

The different samples produced were put under different chemical environmental conditions, namely: in distilled water, in acidic solution, in basic solution and in saline solution. The acid solutions were produced from a $1 \mathrm{M}$ hydrochloric acid solution, the basic solution by dissolving sodium hydroxide tablets in distilled water and the saline solution by dissolving $1 \mathrm{~g}$ of sodium chloride in $100 \mathrm{ml}$ of sodium chloride. water is a salinity of $10 \mathrm{~g} / \mathrm{L}$.

The $\mathrm{pH}$ values of the acidic and basic solutions were respectively set at $\mathrm{pH}=2$ for the acids and $\mathrm{pH}=9$ for the basic solutions. The $\mathrm{pH}$ values were determined using a TACCUSSEL brand $\mathrm{pH}$ meter. The choice of these $\mathrm{pH}$ values is that of products of current consumption. Drinks such as pineapple, orange and lemon juices have a $\mathrm{pH}$ that oscillates between 2 and 4. Salinity solutions below $10 \mathrm{~g} /$ liter are consistent with the diet that ensures prevention against diseases caused by consumption of foods of high salinity. The study consisted of measuring the variation in mass of the samples over a period of 75 days during which the samples were in continuous contact with these solutions. This duration, which corresponds to 2 months and two weeks, could correspond to that of a product from its conception to its end of life.

\section{RESULTS}

Tables 1, 2 and 3 illustrate the chemical stability of the composite film based on cassava starch plasticized with glycerol after 75 days of exposure in different environment: acidic, basic, saline and distilled water. 
Table 1. Film samples without fibers and without lime

\begin{tabular}{|c|c|c|c|c|}
\hline & $\begin{array}{l}\text { Acidic } \\
\text { environment } \\
\mathrm{pH}=2\end{array}$ & $\begin{array}{l}\text { Basic } \\
\text { environment } \\
\mathrm{pH}=9\end{array}$ & $\begin{array}{l}\text { Saline } \\
\text { environment } \\
10 \mathrm{~g} / \mathrm{L}\end{array}$ & $\begin{array}{l}\text { distilled } \\
\text { water }\end{array}$ \\
\hline $\begin{array}{l}\text { Mass } \\
\text { loss } \\
\text { in } \%\end{array}$ & 56,2 & 60,7 & 35,1 & 42 \\
\hline
\end{tabular}

Table 2. Film samples with lime and without fibers

\begin{tabular}{|l|l|l|l|l|}
\hline & $\begin{array}{l}\text { Acidic } \\
\text { environment } \\
\mathrm{pH}=2\end{array}$ & $\begin{array}{l}\text { Basic } \\
\text { environment }\end{array}$ & $\begin{array}{l}\text { Saline } \\
\text { environment } \\
\mathrm{pH}=9\end{array}$ & $\begin{array}{l}\text { distilled } \\
\text { water }\end{array}$ \\
\hline $\begin{array}{l}\text { Mass } \\
\text { loss } \\
\text { in\% }\end{array}$ & 17,3 & 55,1 & 9,4 & 14,2 \\
\hline
\end{tabular}

Table 3. Film samples with lime and fibers

\begin{tabular}{|l|l|l|l|l|}
\hline & $\begin{array}{l}\text { Acidic } \\
\text { environment } \\
\mathrm{pH}=2\end{array}$ & $\begin{array}{l}\text { Basic } \\
\text { environme } \\
\mathrm{nt}\end{array}$ & $\begin{array}{l}\text { Saline } \\
\text { environmen } \\
\mathrm{t}\end{array}$ & $\begin{array}{l}\text { distill } \\
\text { ed } \\
\text { water }\end{array}$ \\
$\mathrm{pH}=9$ & $10 \mathrm{~g} / \mathrm{L}$ & \\
\hline $\begin{array}{l}\text { Mass } \\
\text { in\% }\end{array}$ & $\approx 2$ & 53,4 & $\approx 1,1$ & $\approx 1,7$ \\
\hline
\end{tabular}

solution. When adding lime (Table 2), the mass loss rates drop considerably in the acid $(17.3 \%)$, saline $(9,4 \%)$ and distilled water $(14.2 \%)$ unlike the basic solution $(55.1 \%)$. However, the losses remain in the same order. Finally, Table 3 specifies the effect of coconut fibers when incorporated into the composite. Indeed, for reinforced films, the rate of mass loss becomes very low in acid $(2 \%)$, saline $(1.1 \%)$ and distilled water $(1.7 \%)$ solutions, while chemical resistance in the basic solution remains undesirable $(53.4 \%)$.

\section{DISCUSSION}

After 75 days of exposure of the samples in different chemical environment, the material was found to have good chemical resistance in acidic, saline and distilled water solutions. It has low chemical resistance behavior in basic solution. This low resistance is due to the presence of starch which is hydrolyzable [2][3][4]. These results show that films, by virtue of their origin, are attacked by the environments in which they are exposed. In the following, we make proposals to explain the process of dissolution of the composite in the different solutions.

\section{IV.1. Aqueous environment}

It can be seen that the loss of mass of the samples without lime or reinforcements is very high, ie $42 \%$, to $14.2 \%$ after the addition of lime. Lime is a mineral phase: $\mathrm{CaO}$. In an organic environment such as that of the film, it would be expelled from the network towards the surface of the

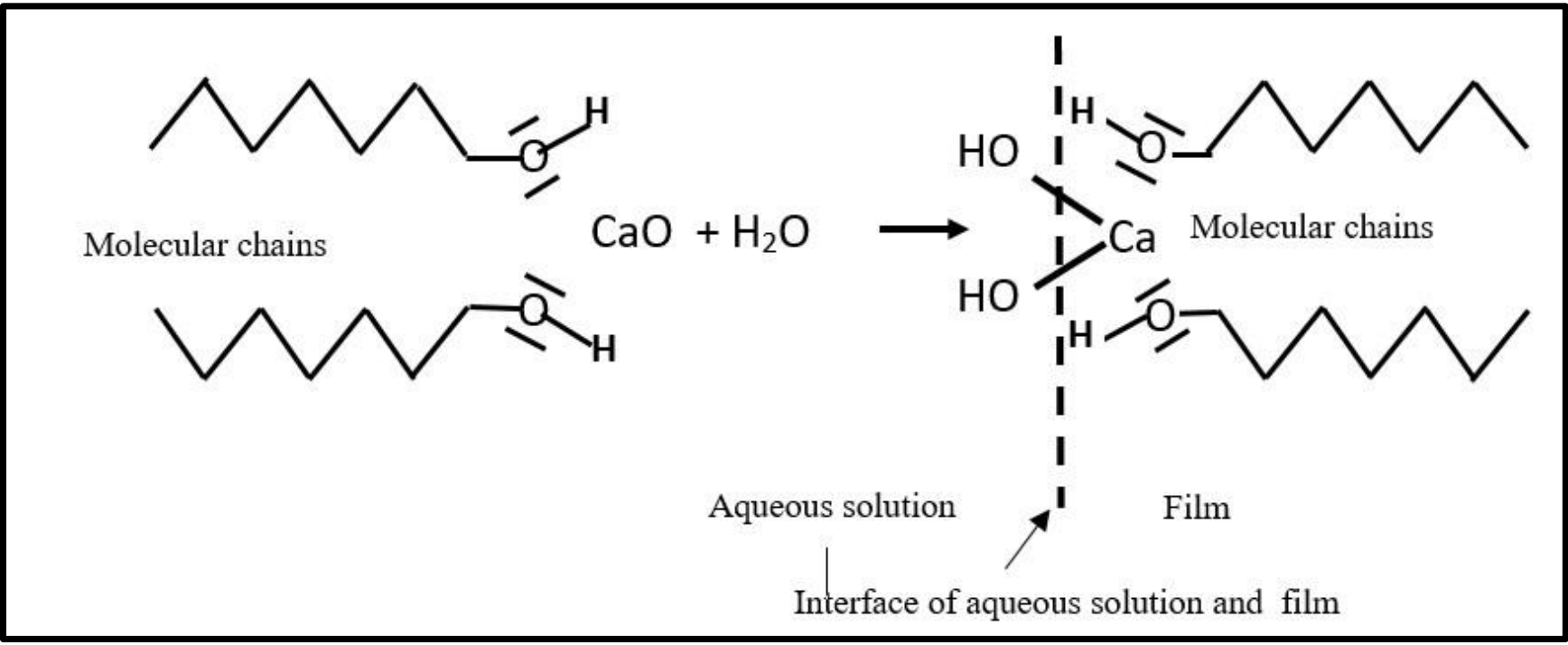

Fig. 1 Diagram of the foration of hydroxide at the interface under the action of lime

Table 1 shows that the unreinforced film without the addition of lime has a high rate of mass loss in the basic solution $(60.7 \%)$ compared to others where the dissolution rates are lower. For example, we have a value of $35.1 \%$ in the saline
Sample. Upon reaction with water, it would form calcium hydroxide : $\mathrm{Ca}(\mathrm{OH})_{2}$. This molecule would be oriented so that the $-\mathrm{OH}$ hydroxides are directed outwards while the calcium 
of positive susceptibility $+\delta$ would be in interaction with the free doublets of the hydroxides inside the matrix (Fig. 1).

The availability of hydroxide groups at the surface would lower the water gradient at the film-water interface. With the absence of lime in the matrix, the diffusion of water would be favored. Water entering the film would swell there which would cause the film plane to detach, causing significant loss. With the reinforcements, we introduce an additional barrier to the diffusion of water. The swelling process would be further reduced and the losses drop drastically to less than $1.7 \%$ after 75 days of contact.

\section{IV.2. Saline environment}

In a saline environment, $10 \mathrm{~g} / \mathrm{L}$, there is less loss compared to water during contact with the matrix: $35.1 \%$ compared to $42 \%$. A barrier has obviously formed limiting the process seen in distilled water. If in solution the sodium $\mathrm{Na}+$ ions are solvated, the chloride ions $\mathrm{Cl}$ - are less so because of their large size. These poorly solvated ions would accumulate at the interface, creating hydrogen bridges with the protons of the hydroxide groups at the interface, reducing the swelling and detachment of the films somewhat (Fig. 2)

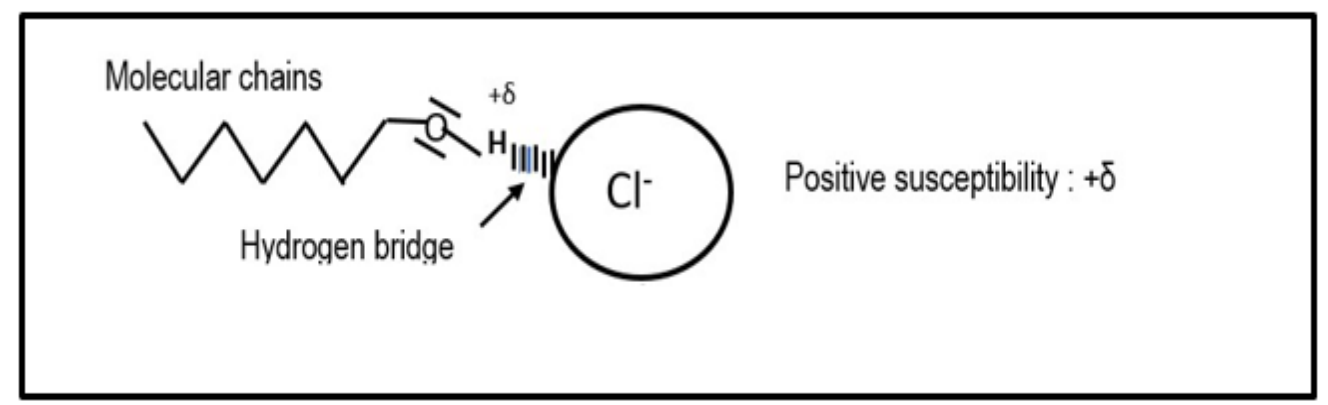

Fig. 2 Hydrogen bridge between chloride ion and hydrogens at the saline film interface

With the addition of lime, the two combined phenomena lead to an improvement in stability to reach $9.4 \%$ loss when it is $14.2 \%$ in distilled water. The stability of the film naturally becomes better with the presence of reinforcements since they would reduce the diffusion of water. The mass loss is lower: $1.1 \%$.

\section{IV.3. Basic environment}

In a basic solution $\mathrm{pH}=9$, the loss is very significant regardless of the sample. If it seems greater than in distilled water, $60.7 \%$, the losses remain however of the same order for the samples containing lime and the reinforcements:
$55.1 \%$ and $53.4 \%$. Basic solutions characterized by $\mathrm{OH}-$ hydroxide ions would therefore be responsible. However, these values should be brought back to the case of distilled water. Indeed, the phenomenon of mass loss here would be the sum of the loss due to water which is the solvent. The difference in mass loss would therefore be due to the aggression of the films by hydroxides, here $18.7 \%$. The hydroxide ions could attack the carbons in the more electropositive $\alpha$ position and cause destruction of the film. This possibility is illustrated on the D-glucose model (Fig. 3). Under such conditions, the fibers which are cellulose would also be attacked, canceling any barrier effect to destruction.

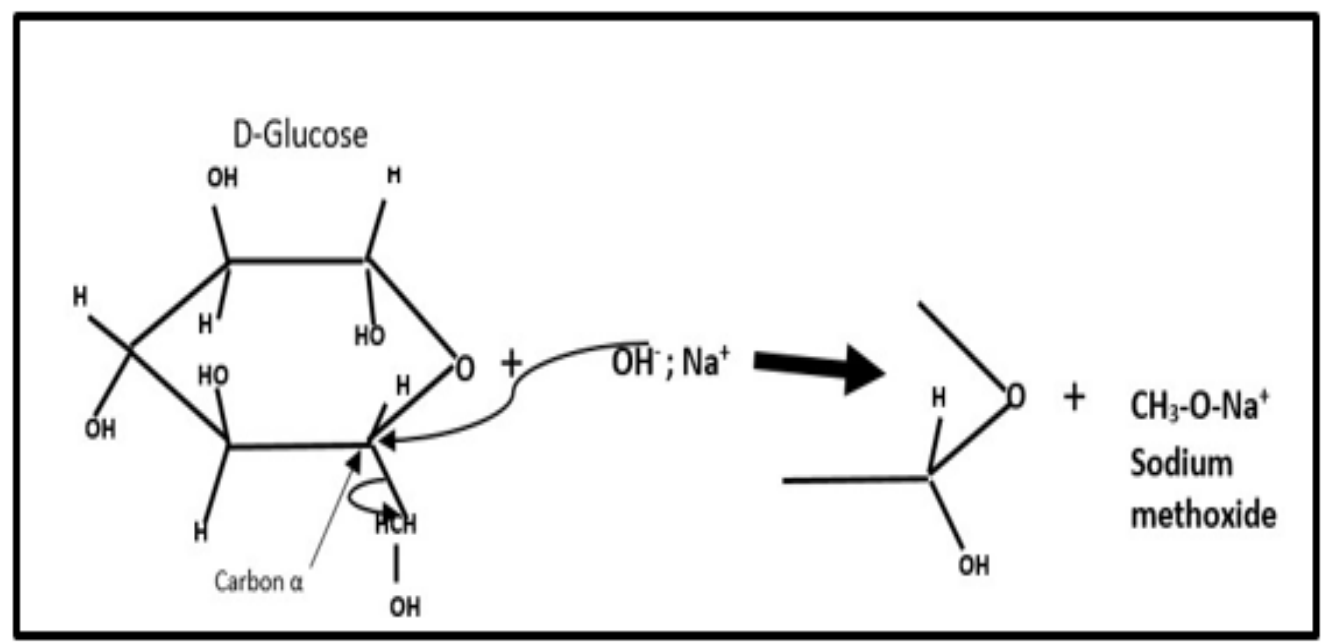

Fig. 3 Dissolution process of films in a basic solution

The hydroxide ion would attack the susceptibility $\alpha$ carbon + $\delta$. The carbon electron of the $\mathrm{CH}_{2}-\mathrm{OH}$ group would be returned to it to drive the transient species $-\mathrm{CH}_{2}-\mathrm{OH}$ with a $\mathrm{C}$ - carbanion. The anion would rearrange itself into the methylate ion $\mathrm{CH} 3-\mathrm{O}-$, which together with the sodium ion would form sodium methoxide which dissolves in solution, causing mass loss. 


\section{IV.4. Acidic environment}

In the case of the acidic solution with the matrix only, as in the case of the basic solution, the effect of water which leads to swelling loss is also present. The loss of mass which would be due to the acidity of the environment is therefore $14.2 \%$.
The action of $\mathrm{H}+$ protons could be illustrated by the protonation of hydroxides at the surface leading to the formation of water molecules which would lead to the loss of an $\mathrm{OH}$ group and the formation of a carbocation stabilized by the chloride ion (Fig. 4).

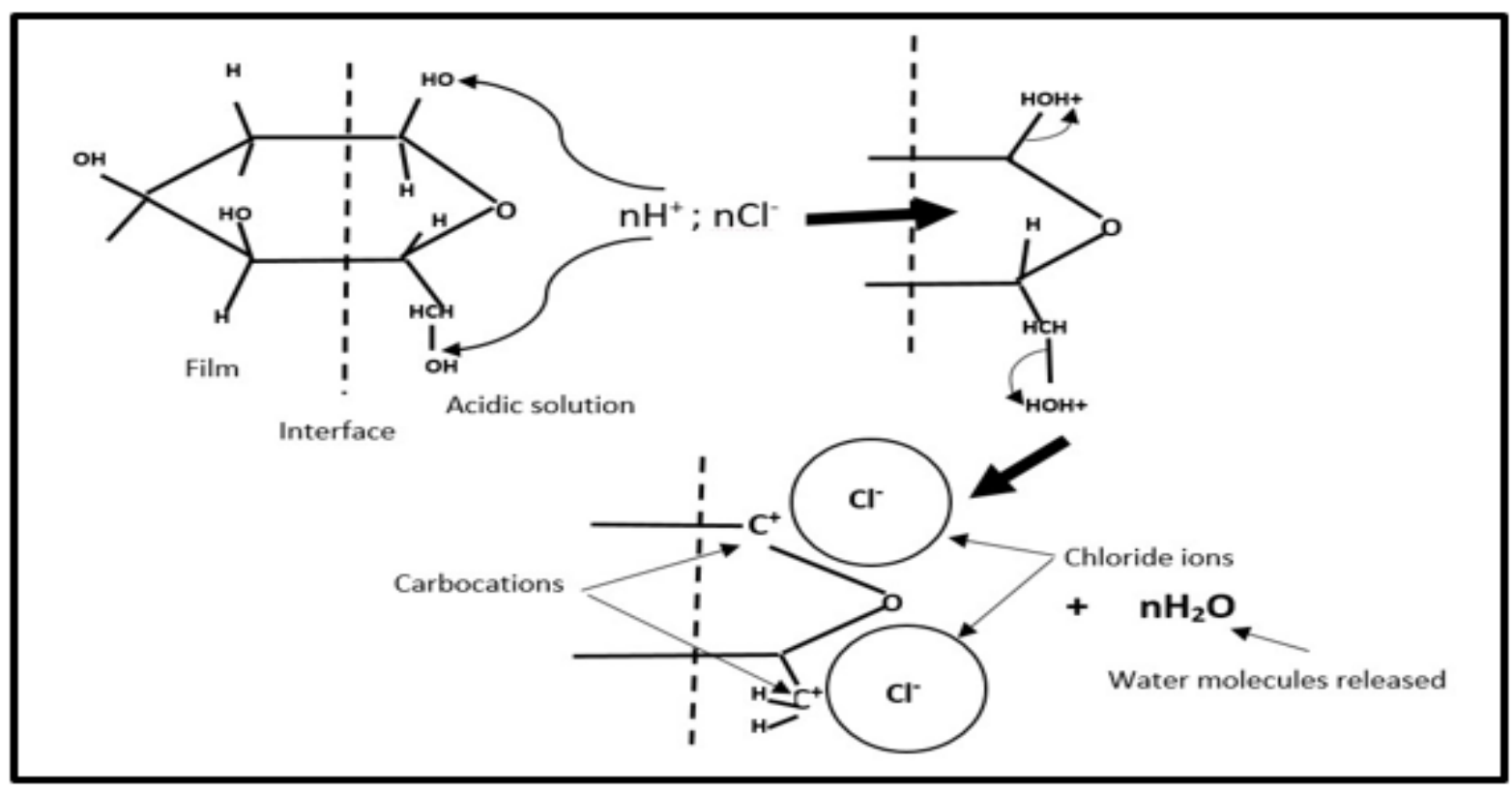

Fig. 4 Loss of mass by release of water in an acidic solution

The size of the chloride ions being very large to compare to that of carbon, their adsorption would induce an obstruction of the surface of the film reducing at the same time access to water molecules and which would have caused swelling and loss of material. .

With the samples containing lime, the $\mathrm{OH}$ groups of the calcium which points would also be protonated, releasing a positive site on the calcium which, in reaction with a molecule, of water would restore the proton consumed and would replace the lost hydroxide. . Therefore, no loss of mass should be attributable to the action of protons. The $17.3 \%$ mass loss would therefore be due to water. However, the chloride ions which occupy all or part of the surface would clearly reduce this effect (Fig. 5).

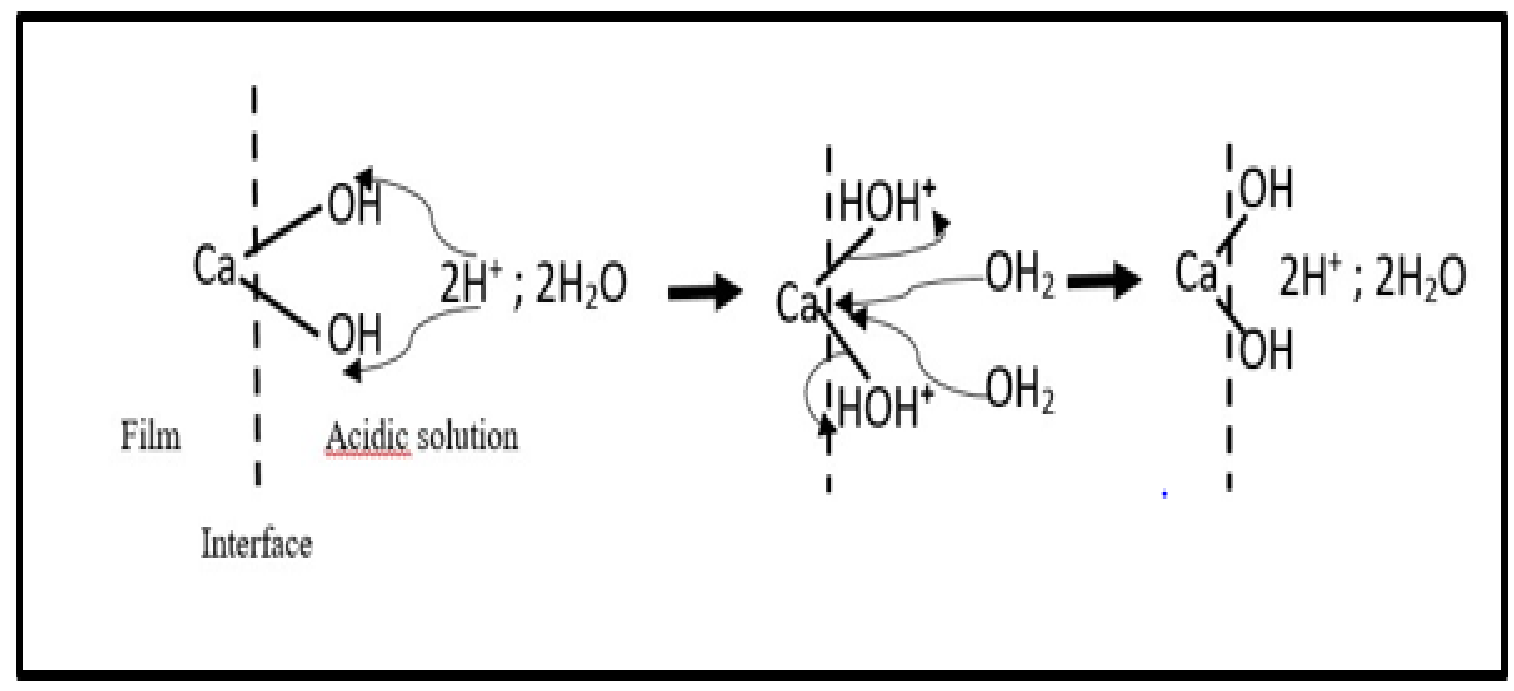

Fig. 5 Interface stability in an acidic environment $\mathrm{pH}=2$

In the presence of reinforcement, the loss of mass is only of the order of $2 \%$. The barrier character noted in the case of water and saline solution would intervene here to reduce the penetration of water into the material. What's more, the fibrous state of the reinforcements would make them more stable against proton attack. 


\section{CONCLUSION}

The observations made during this study provide information on the possible use of this material for the preservation of products. Thus, the phases whose acidity is of the order of $\mathrm{pH}$ $=2$, of salinity of the order of $10 \mathrm{~g} / \mathrm{L}$ could be preserved in the composites treated with lime. Conversely, basic solutions cannot be stored there since the packaging will experience very significant deterioration until a loss of mass of more than half. This composite, with proven water stability, could also be used as a packaging for dry products such as legumes, cookies, peanuts, and salted cashew kernels. However, for the preservation of food phases, a toxicity study should be undertaken.

\section{REFERENCES}

1. Ahmed Doumbia, Pierre J.-M. R. Dable, Edja F. Assanvo, (2018) '"Élaboration et caractérisation d'un matériau biodégradable à base d'amidon de manioc renforcé par les microfibres de mésocarpes de coco", Afrique SCIENCE, 14(5) pp. 400 - 414

2. Assanvo E. F.,(Doctorat thesis, 2015) " Modification of RicinodendronHeudelotii oil for bio-based coating", CSIR-North East Institute of Science and Technology, Jorhat 785006, Assam, India

3. Suresh S. N., Xiaohua K., Leila H., (2009) ,Biomacromolecules, 10, pp. 884 -891

4. Dutta N., Karak N., Dolui S. K., (2004), Prog. Org. Coat., 49, pp. 146-152 